\title{
Management of Antibiotic-Resistant Helicobacter pylori Infection: Perspectives from Vietnam
}

\author{
Vu Van Khien ${ }^{1}$, Duong Minh Thang ${ }^{1}$, Tran Manh $\mathrm{Hai}^{2,3}$, Nguyen Quang Duat ${ }^{4}$, Pham Hong Khanh ${ }^{4}$, Dang Thuy Ha ${ }^{5}$, Tran \\ Thanh Binh ${ }^{6}$, Ho Dang Quy Dung ${ }^{6}$, Tran Thi Huyen Trang ${ }^{2}$, and Yoshio Yamaoka ${ }^{7}$ \\ Departments of ${ }^{1}$ GI Endoscopy and ${ }^{2}$ Molecular Biology, 108 Central Hospital, ${ }^{3}$ University of Science and Technology of Hanoi, ${ }^{4}$ Department \\ of Gastroenterology, 103 Hospital, ${ }^{5}$ Department of Gastroenterology, National Children Hospital, Hanoi, ${ }^{6}$ Department of Endoscopy, Cho Ray \\ Hospital, Ho Chi Minh City, Vietnam, and ${ }^{7}$ Department of Environmental and Preventive Medicine, Oita University Faculty of Medicine, Oita, \\ Japan
}

Antibiotic resistance is the most important factor leading to the failure of eradication regimens. This review focuses on the prevalence of Helicobacter pylori primary and secondary resistance to clarithromycin, metronidazole, amoxicillin, levofloxacin, tetracycline, and multidrug in Vietnam. We searched the PubMed, EMBASE, Vietnamese National Knowledge Infrastructure, and Vietnamese Biomedical databases from January 2000 to December 2016. The search terms included the following: $H$. pylori infection, antibiotic (including clarithromycin, metronidazole, amoxicillin, levofloxacin, tetracycline, and multidrug) resistance in Vietnam. The data were summarized in an extraction table and analyzed manually. Finally, Excel 2007 software was used to create charts. Ten studies (three studies in English and seven in Vietnamese) were included in this review. A total of 308, 412, 523, 408, 399 , and $268 \mathrm{H}$. pylori strains were included in this review to evaluate the prevalence of $H$. pylori primary resistance to amoxicillin, clarithromycin, metronidazole, levofloxacin, tetracycline, and multidrug resistance, respectively. Overall, the primary resistance rates of amoxicillin, clarithromycin, metronidazole, levofloxacin, tetracycline, and multidrug resistance were 15.0\%, 34.1\%, 69.4\%, 27.9\%, 17.9\% and $48.8 \%$, respectively. Secondary resistance rates of amoxicillin, clarithromycin, metronidazole, levofloxacin, tetracycline, and multidrug resistance were 9.5\%, 74.9\%, 61.5\%, 45.7\%, $23.5 \%$ and $62.3 \%$, respectively. In Vietnam, primary and secondary resistance to $H$. pylori is increasing over time and affects the effectiveness of $H$. pylori eradication. (Gut Liver 2019;13:483-497)

Key Words: Helicobacter pylori; Amoxicillin; Bismuth; Clar- ithromycin; Metronidazole

\section{INTRODUCTION}

In 1983, Marshall and Warren ${ }^{1}$ discovered Helicobacter pylori-a gram-negative bacillus that infects the human stomach mucosa. Further studies confirmed that $H$. pylori is the main cause of chronic gastritis, peptic ulcer disease, gastric marginal zone/mucosa-associated lymphoid tissue (MALT) lymphoma and gastric carcinoma. ${ }^{2-7}$ Recently, it has been suggested that $H$. pylori may be associated with extraintestinal diseases, including immune thrombocytopenic purpura, refractory iron deficiency anemia and vitamin $\mathrm{B}_{12}$ deficiency. ${ }^{8,9}$ Globally $H$. pylori has been classified as a class I carcinogen and the major cause of gastric cancer. ${ }^{10}$

In Vietnam, frequency of $H$. pylori infection is rather popular and similar to that in the other developing countries. A largescale study showed that frequency of $H$. pylori infection made up over 70\% in adults and lightly reduced in children. ${ }^{11-14}$ An investigation study in a hospital indicated that frequency of $H$. pylori infection was 59.9\% to 69.9\% for chronic gastritis; $77.8 \%$ for gastric ulcer; $85 \%$ to $95 \%$ for duodenal ulcer and $85.3 \%$ to 93.6\% for gastroduodenal ulcer. ${ }^{14-16}$

Generally, H. pylori eradication is indicated in cases of peptic ulcer including active, non-active and complicated, gastric MALT lymphoma, and to some extent, chronic gastritis and functional dyspepsia. Eradication of $H$. pylori not only heals peptic ulcers, but also prevents their recurrence and reduces the risk of development of gastric cancer. ${ }^{17-21}$ In addition, diseases related to $H$. pylori such as MALT lymphoma, gastric atrophy and intestinal dysplasia are also recoverable after antibiotic

Correspondence to: $\mathrm{Vu}$ Van Khien

Department of GI Endoscopy, 108 Central Hospital, No 1, Tran Hung Dao Street, Hanoi 113601, Vietnam

Tel: +84-4-988-455-388, Fax: +84-4-8250-000, E-mail: vuvankhien108@yahoo.com.vn

Received on March 19, 2018. Revised on November 13, 2018. Accepted on November 27, 2018. Published online April 23, 2019 pISSN 1976-2283 eISSN 2005-1212 https://doi.org/10.5009/gnl18137

() This is an Open Access article distributed under the terms of the Creative Commons Attribution Non-Commercial License (http://creativecommons.org/licenses/by-nc/4.0) which permits unrestricted non-commercial use, distribution, and reproduction in any medium, provided the original work is properly cited. 
treatment. $^{22,23}$

Triple therapy regimens including one proton pump inhibitor (PPI) and two antimicrobial agents such as amoxicillin (A), clarithromycin (C), metronidazole (M), levofloxacin (L), and tetracycline $(\mathrm{Te})$ have been widely used to eradicate this bacterium. Although rate of successful eradication treatment depends on many factors such as smoking and patients' compliance, antibiotic resistance is an important factor reducing treatment efficiency. ${ }^{24,25}$ Rate of the antibiotic resistance is higher in the developing countries than in the developed countries. ${ }^{26,27}$ In addition, the rate of antibiotic resistance often correlates with the amount of antibiotics consumed in the population. ${ }^{3,28-30}$ In Vietnam, based on International Consensus, regimens of using two antibiotic drugs: clarithromycin and amoxicillin, or clarithromycin and metronidazole, are standard regimen to eradicate $H$. pylori. ${ }^{20,31,32}$ In Vietnam, in early 1990s, rate of $H$. pylori eradication exceeded 90\%. However, recent statistics indicate that $H$. pylori eradication rate has decreased to $60 \%-70 \%$. The most important cause for the reduced success of standard triple therapy is the increasing rate of $H$. pylori clarithromycin/metronidazole/levofloxacin resistance. ${ }^{33-35}$ In this review, we provide the following information: (1) frequency of $H$. pylori infection in Vietnam; (2) rate of $H$. pylori infection in chronic gastritis, gastric ulcer and gastric cancer in Vietnam; (3) efficiency of $H$. pylori eradication regimen in Vietnam; (4) antibiotic resistance rate of $H$. pylori in Vietnam; (5) the cause of $H$. pylori resistance in Vietnam; or (6) perspectives from Vietnam.

The data was summarized in extraction table and analyzed manually. Finally, Excel 2007 software (Microsoft, Redmond, WA, USA) was used to draw charts.

\section{Prevalence and risk factors of $H$. pylori infection in Vietnam}

There is a difference in rate of $H$. pylori infection among the Asian countries and even in a country. ${ }^{36}$ The rate of $H$. pylori infection depends on socio-economic and environmental conditions. Frequency of $H$. pylori infection in the developing countries is often higher than that in the developed countries. In developing countries such as India and Saudi Arabia and African countries, the infection rate is high and approximately $80 \%$ of the population infected with $H$. pylori by 20 years old. ${ }^{37}$ In contrast, the infection rate is reported to be as low as $10 \%$ to $20 \%$ in developed countries, and the infection rate increases at a rate of approximately $1 \%$ per year. ${ }^{38}$ In Japan, the rate of $H$. pylori infection in children under the age of 10 is very low (approximately 5\%) and the rate of $H$. pylori infection gradually increases by ages. ${ }^{39}$

Vietnam is in the center of Southeast Asia Region and in the East of the Indochinese Peninsula and borders Chinese to the North, Laos and Cambodia to the West and the South China Sea and Pacific Sea to the Southeast. Vietnam has its population of about 94 million people and 54 ethnic groups, including over $80 \%$ of Kinh group. Vietnam divided into three different areas:
Northern Vietnam (25 provinces), Central Vietnam (19 provinces), and Southern Vietnam (19 provinces). There are three main cities: Hanoi, Hue, and Ho Chi Minh City. Fig. 1 shows the map of Vietnam, with three different regions (north, central, and south), with three major cities in Vietnam (Hanoi, Hue, and Ho Chi Minh City).

Vietnam does not have a national survey of $H$. pylori infection epidemiology. The study only focused on some areas in major cities, or delta. These studies also focus only on Kinh people. Before 2010, there was no study on the epidemiology of $H$. pylori in the ethnic group

In 2005, Hoang et al. ${ }^{11}$ conducted epidemiologic investigation of $H$. pylori infection rate in the community, including children and adults, through serological test, in urban (Hanoi) and rural Vietnam (Hatay province). Study results indicated that the rate of $H$. pylori infection in community was $74.6 \%$. The rate of $H$. pylori infection in Hanoi (78.8\%) was higher than that in Hatay (69.2\%). This difference was significant $(\mathrm{p}=0.0007)$. These study results showed that the rate of $H$. pylori infection in the community in Vietnam is very high, especially in the urban areas (Hanoi). They proved that the frequency of $H$. pylori infection has gradually increased by ages, particularly at the age of 30 and above. The rate of $H$. pylori infection at the age of 30, 52, 59 and 83 is 33.3\%, 49.2\%, 69.2\%, and 78.3\%, respectively. ${ }^{11}$ The study shows that the prevalence of $H$. pylori infection is high in Vietnam and especially high in large urban, such as the city of Hanoi.

Prevalence of $H$. pylori infection is also high in children. A study of Nguyen et al. ${ }^{12}$ on 284 children at 6 months and 15

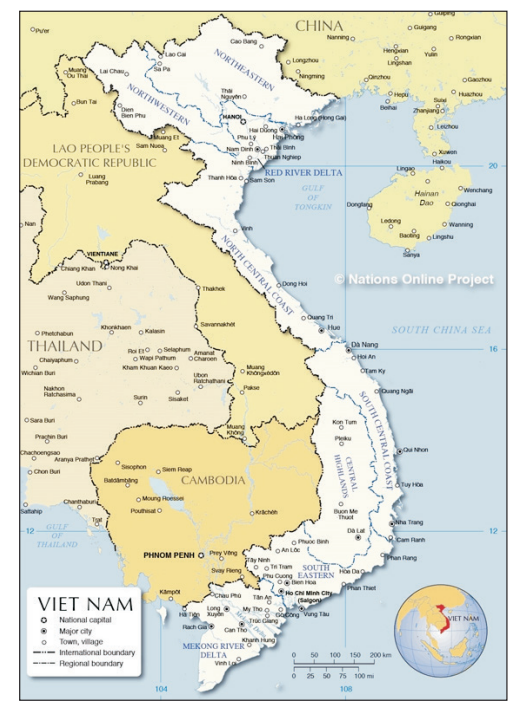

Fig. 1. Map of Vietnam with three different regions: North, Central, and South. Note: North Vietnam includes northwestern, northeast and Red River Delta areas. Central Vietnam includes north central coast, south central coast and central highlands. South Vietnam includes southeastern and Mekong River Delta areas. Reprinted with the permission of Nations Online Project. 
years, through serological test showed that the rate of $H$. pylori infection in children was 34.0\%. Study examined the relationship between $H$. pylori infection and a number of factors, including: sociodemographic characteristics, health status, environmental status, health status, and so on. Study concluded that person-to-person transmission and sociodemographic factors are factors associated with $H$. pylori infection

Besides the serological test, urine tests are conducted to investigate the rate of $H$. pylori infection in community, as well as applied for people with gastric diseases. Nguyen et al. ${ }^{15}$ found that Rapirun test had sensitivity, specificity and accuracy rate of $79.5 \%, 90.7 \%$, and $84.5 \%$, respectively. These results were similar to those of Quach et al..$^{40}$ upon testing and finding $H$. pylori in 200 patients by Rapirun Stick test to obtain sensitivity, specificity and accuracy rate of 84.7\%, 89.9\%, and 87\%, respectively. However, these urine tests only helped investigation of $H$. pylori infection rate in community.

Recently, there have been some epidemiological investigation of $H$. pylori infection rates in ethnic, including adults and children. ${ }^{41-44}$ In 2014, Binh et al., ${ }^{41}$ investigated $H$. pylori infection rates (five different methods) on 494 volunteers. Research subjects are ethnic in two different areas: Lao Cai province (North Vietnam), Daklak Province (Central Vietnam). Results of the study indicate that the prevalence of $H$. pylori infection among ethnic minorities (adults) was 188 out of 494 (38.1\%). There were significant differences in rates of $H$. pylori infection in Daklak and Lao Cai (51.0\% vs 29.3\%, p<0.001). There are many factors may contribute to $H$. pylori infection such as geographical location, ethnicities, dietary habit, etc. The results showed that subjects living in Daklak had a significantly higher risk of $H$. pylori infection than those in Lao Cai (crude odds ratio [OR], 2.52; 95\% confidence interval [CI], 1.73 to 3.65). With respect to minor ethnic groups, E De (crude OR, 2.44; 95\% CI, 1.64 to 3.62) was at significantly higher risk, whereas Tay (crude OR, 0.3095\%; CI, 0.16 to 0.56 ) and Dao (crude OR, 0.37; 95\% CI, 0.17 to 0.73) were at significantly lower risk of $H$. pylori acquisition.

Nguyen et al. ${ }^{42}$ was studied the epidemiology of $H$. pylori infection in Khmer children in Mekong Delta (South Vietnam). Research results showed that the prevalence of $H$. pylori infection among children of Khmer ethnicity is $32.1 \%$. H. pylori infection in mothers, in first sibling and in two first siblings in particular were found as high-risk factors for $H$. pylori infection in children (OR, 1.98; 95\% CI, 1.12 to 3.18; OR, 2.12; 95\% CI, 1.2 to 4.12 ; OR, 4.39; 95\% CI, 2.81 to 6.94 ; respectively).

According to the statistics of the Government of Vietnam (2009), the Tay is the second largest ethnic group in Vietnam after the majority Kinh ethnic. Tay people live mainly in the mountains of northern Vietnam. Nguyen et al. ${ }^{43}$ showed that epidemiology of $H$. pylori infection in Tay children (Lang Son province-North Vietnam). Study concluded that intra-familial $H$. pylori transmission are factors associated with $H$. pylori infection. In 2017, Nguyen et al. ${ }^{44}$ also investigated the epidemiol- ogy of $H$. pylori infection in Muong people. Muong is the thirst largest ethnic group in Vietnam after the majority Kinh and Tay ethnic group. The findings showed a familial clustering in these multi-generation familial structures and supported the hypothesis of person-to-person transmission in $H$. pylori infection.

Limitations of the study in Vietnam focused on the region and the number of volunteers has less. ${ }^{41-44}$ However, the above studies show that family, race, geography, life-style and age are related to $H$. pylori infection in Vietnam.

Today, the economic conditions of Vietnam are going up, improve public sanitation, improve health care, could also be a factor in reducing the rate of $H$. pylori infection in the community. However, to demonstrate this matter, should have investigated the epidemiology of $H$. pylori infection nationwide.

In Korea, Lim et al. ${ }^{45}$ has evaluated the time trend of seropositivity of $H$. pylori over the period of 13 years in an asymptomatic Korean population, and investigate associated risk factors. The overall seroprevalence of $H$. pylori infection was 54.4\% (95\% CI, $53.5 \%$ to $55.4 \%$ ) in 2011 which is significantly decreased from 66.9\% (95\% CI, 65.4\% to 68.6\%) in 1998, and 59.6\% (95\% CI, 58.5 to $60.7 \%$ ) in 2005 ( $\mathrm{p}<0.001)$. Factors including elderly, male gender, low income, residence in a rural area and high cholesterol ( $\geq 240 \mathrm{mg} / \mathrm{dL}$ ) (OR, 1.33; 95\% CI, 1.14 to 1.54 ) are related to $H$. pylori infection.

\section{PREVALENCE H. PYLORI INFECTION IN GASTRIC DISEASES IN VIETNAM}

\section{Prevalence $\boldsymbol{H}$. pylori infection in patients with chronic gastritis}

Chronic gastritis is rather popular among the gastric diseases. But the studies of the rate of $H$. pylori infection in patients with chronic gastritis focused on Kinh group. In 2003, Long et al. ${ }^{46}$ collaborated with Fukui University (Japan) to determine the rate of $H$. pylori infection by three methods: urease test, histopathology and serological test (ELISA) in 104 patients with gastric cancer and 104 patients with chronic gastritis. Study results indicated that the rate of positive $H$. pylori infection on the tests: urease test, histopathology and serological test was $44.5 \%$; $57.6 \%$ and $88.1 \%$, respectively.

Thang $^{47}$ found that the rate of $H$. pylori infection in patients with chronic gastritis $(\mathrm{n}=235)$ was $75.9 \%$ (determined by histopathology and CLO test). Thinh ${ }^{48}$ using four various methods: urease test, polymerase chain reaction (PCR), histopathology and culture showed that the rates of $H$. pylori infection were 58.1\%, $58.1 \%, 56.3 \%$ and 57.0\%, respectively. Dung ${ }^{49}$ also obtained similar results, with the rate of 59.9\%. Thus, these study results proved that the rate $H$. pylori infection in patients with chronic gastritis in Kinh group is rather high.

Recently, studies of the frequency of $H$. pylori infection in the ethnic groups of Vietnam have been conducted. Binh et al. ${ }^{41}$ conducted a study of the rate of $H$. pylori infection in the eth- 
nic groups in Daklak (Central Highlands-Vietnam) and Lao Cai (North Vietnam). The author used four combined methods; including culture, histopathology-immunohistochemical, test urease and serological test. Study results pointed out that the rate of $H$. pylori infection was 188 out of 494 (38.1\%), in which the rate of $H$. pylori infection in Lao Cai province (51.0\%) significantly increased (crude OR, 2.52; 95\% CI, 1.73 to 3.65) higher than that in Daklak province (29.3\%).

\section{Prevalence of $\boldsymbol{H}$. pylori infection in patients with gastro- duodenal ulcer in Vietnam}

There are two main causes of gastric duodenal ulcer: using nonsteroidal anti-inflammatory drugs and $H$. pylori infection. Many studies of the rate of $H$. pylori infection in patients with gastric duodenal ulcer have been conducted.

A study of Long ${ }^{50}$ on 300 patients with gastroduodenal ulcer pointed out that the rate of $H$. pylori infection was 91.7\%. A study of Huong ${ }^{51}$ on patients with gastroduodenal ulcer in Hue National Hospital for 2 years (1998 to 1999), the rate of $H$. pylori infection was $72.6 \%$, while the rate of $H$. pylori infection in patients with duodenal ulcer was 79.1\%.

Nguyen et al. ${ }^{14}$ combined five different methods (urease test, histopathology, culture, serological test, and immunohistochemical) to determine that rate of $H$. pylori infection on 270 patients, including gastric ulcer $(n=38)$, chronic gastritis $(n=245)$, gastroesophageal reflux disease $(n=9)$, and normal $(n=25)$. Study results showed that the rate of $H$. pylori infection was 177 out of $270(65.6 \%)$. There is no significant difference in the rate of $H$. pylori infection between male and female patients (66.0\% and 65.0\%) as well as between Hanoi and Ho Chi Minh City (66.4\% and $64.7 \%)$.

\section{Prevalence of $\boldsymbol{H}$. pylori infection in patients with gastric cancer}

Globally $H$. pylori has been classified as a class I carcinogen and the major cause of gastric cancer. ${ }^{10}$ Many studies focused on the relation between the gastric cancer and the rate of $H$. pylori infection, virulence factors of $H$. pylori (cagA, vacA, etc.). Hop and Tho ${ }^{52}$ studied on 205 patients with gastric cancer and the rate of $H$. pylori infection was 136 out of 250 (66.3\%). Long et $a{ }^{46}{ }^{4}$ found that the rate of positive $H$. pylori infection in patients with gastric cancer on the tests $(n=104)$ : Urease test, histopathology and serological test (ELISA) was 55.1\%, 71.1\%, and $90.6 \%$, respectively. Binh et al. ${ }^{41}$ found that the rate of positive $H$. pylori infection by four methods (culture, histopathology, urease test, and serological test) on 282 in patients with gastric cancer was 224 out of 282 (79.4\%). There is no difference in the rate of $H$. pylori infection in patients with gastric cancer between in Hanoi (77.3\%) and in Ho Chi Minh City (80.5\%).

These results showed that the frequency of $H$. pylori infection increased not only in community but also in gastric diseases (chronic gastritis, gastric ulcer, duodenal ulcer, and gastric can- cer). Further studies of virulence factor of $H$. pylori (cagA and vacA) indicated close relation between $H$. pylori infection and the gastric diseases in Vietnam. ${ }^{14,15,53}$ Therefore, $H$. pylori eradication is necessary, especially in patients with chronic gastritis and gastric duodenal ulcer.

\section{EFFICIENCY OF H. PYLORI ERADICATION REGIMEN IN VIETNAM}

\section{Efficiency of $H$. pylori eradication by first-line therapy}

Triple therapy has been early and widely used in three regions of Vietnam (North, Central, and South Vietnam). In the decade: 1990 to 2000, when there had not been the antibiotic resistance, the triple therapy had been widely applied in clinical treatment in Vietnam. The triple therapy includes a proton pump inhibitors (PPI) and two antibiotics. PPIs having been used in Vietnam consist of omeprazole, lansoprazole, pantoprazole, rabeprazole and esomeprazole. There are three antibiotics commonly used in legacy triple therapies including clarithromycin (CLR), amoxicillin (AMX), metronidazole (MNZ).

The appropriate regimen is to achieve the following criteria: ${ }^{54}$ (1) Efficacy of eradication of $H$. pylori should be $>90 \%$ as per protocol (PP) and $>80 \%$ according to the intent to treat (ITT); (2) Low side effects, patients' easy to accept and reasonable prices, etc.

Underlying methods in the published papers and analyzed data from different hospitals in Vietnam were selected for this review. All most patients were undergone upper gastrointestinal endoscopy and tested for $H$. pylori (before and after treatment for 30 days).

Diagnosis of $H$. pylori infection by histopathology: two gastric biopsy specimens, one from the antrum and one from the corpus, were fixed in 10\% formalin in separate containers and were sent to the pathology laboratory. Samples were embedded in paraffin wax, cut at $5 \mu \mathrm{m}$ thickness, and stained with modified Giemsa and hematoxylin and eosin. Histological evaluation of the samples for $H$. pylori was performed according to the modified Sydney system.

Rapid urease test (RUT) is the most useful invasive test for the diagnosis of $H$. pylori infection because it is inexpensive, rapid, easy to perform and shows high sensitivity. Several commercial urease tests including gel-based tests (CLO test, HpFast), paper-based tests (PyloriTek, ProntoDry) and liquid-based tests (UFT300, EndoscHp) are available now.

Recently, we also use the breath test to detect $H$. pylori. However, we only use the ${ }^{14} \mathrm{C}$-urease breath test $\left({ }^{14} \mathrm{C}\right.$-UBT $) .{ }^{55}$

Before 2010, techniques for the detection of $H$. pylori infection as UBT, cultures are not applied much (due to lack of equipment and lack of funds). Thus, most studies use RUT and / or histopathology to evaluate the efficacy of $H$. pylori eradication. Two studies have used RUT to detect $H$. pylori infection. ${ }^{56,57}$ One study ${ }^{55}$ used a ${ }^{14} \mathrm{C}-\mathrm{UBT}$. 
Table 1 presents efficiency of triple therapy in treatment for patients with gastroduodenal ulcer due to $H$. pylori infection. The studies are divided into three regions: North Vietnam (seven studies), ${ }^{56-62}$ Central Vietnam (two studies) ${ }^{63,64}$ and South Vietnam (three studies). ${ }^{55,65,66}$ Results showed the rate of $H$. pylori eradication in North Vietnam (67.9\% to 98.1\%) and in Central Vietnam (84.7\% to 90.0\%), higher than that in South Vietnam (62.8\% to $88.2 \%$ ). Maximum efficiency of $H$. pylori eradication in 2002 was $98.1 \%{ }^{59}$ and minimum efficiency of $H$. pylori eradication in 2011 was $62.8 \% .^{57}$

A common feature for three regions indicated that the rate of $H$. pylori eradication has trended to decrease by time, especially in the South Vietnam: $88.2 \%$ in $2009^{65}$ and $62.8 \%$ in $2011 .^{66}$ Similarly, the rate of $H$. pylori eradication in the North Vietnam was very high $98.1 \%$ in $2002^{59}$ but reduced: $67.9 \%$ in $2014 .{ }^{62}$

In the South (Vietnam), due to increased drug resistance, a number of studies have used levofloxacin in first-line regimens (triple therapy) to treat $H$. pylori eradication. ${ }^{55,65}$ However, the results were opposite. Trung et al. ${ }^{55}$ found that no difference in the efficacy of $H$. pylori eradication in EAL regimen (70.2\%) versus EAC regimen (68.3\%). On contrary, $\mathrm{Ngoi}^{65}$ showed efficiency of $H$. pylori eradication in OAL therapy (88.2\%), significantly higher than that in OAC therapy $(68.5 \%)$. Vinh ${ }^{62}$ indicated that the rate of $H$. pylori eradication was only $68 \%$; the rate of clarithromycin resistance was 71 out of 175 (40.6\%) and the rate of amoxicillin resistance was 43 out of 175 (24.6\%).

In Vietnam, for 11 years (2000 to 2011), the rate of $H$. pylori eradication by first line therapy (triple therapy) was significantly reduced: $91.0 \%$ in $2000^{58}$ to $62.8 \%$ in $2011 .^{66}$ Hence, it is required to change treatment strategy using sequential therapy, or concomitant therapy, or bismuth-containing quadruple therapy, or rescue therapy. Based on the world's recommendations and statistic figures of the antibiotic resistance to $H$. pylori, on June 2012, in Ho Chi Minh City, Vietnam Association of Gastroenterology ${ }^{67}$ concluded a consensus of diagnosis and treatment of $H$. pylori infection.

\section{Eradication of $H$. pylori by second-line regimen}

The second indication of $H$. pylori eradication is recommended after the first treatment is unsuccessful. ${ }^{68,69}$ Results of the second $H$. pylori eradication treatment often depends on many factors, in which the antibiotic resistance to $H$. pylori has been increasing, especially clarithromycin/metronidazole/levofloxacin resistance. The Maastricht IV consensus recommended bismuth containing quadruple therapy or levofloxacin containing triple therapy as second-line treatment options. ${ }^{8}$

In Vietnam, from 2009 to 2016, five studies ${ }^{70-74}$ used secondline therapy for $H$. pylori eradication (Table 2). Trung et al. ${ }^{70}$ found that $H$. pylori eradication of the quadruple therapy (EBMT) (95.7\%) was more efficient than the triple therapy (EAL) with levofloxacin $(58.8 \%)(p=0.013)$. This study recommends that levofloxacin should not be used in rescue regimens in Southern Vietnam. $^{70}$

$\operatorname{Vinh}^{71}$ found that the rate of $H$. pylori eradication was higher

Table 1. Results of Helicobacter pylori Eradication in Triple First-Line Therapy in Vietnam

\begin{tabular}{|c|c|c|c|c|c|c|c|}
\hline Author & Local & Year & Regimens & Patient (n) & Time (day) & Method & H. pylori eradication rate \\
\hline \multirow[t]{2}{*}{ Mao et $a l^{58}$} & \multirow[t]{2}{*}{ North } & \multirow[t]{2}{*}{2000} & OAC & 54 & 10 & PyloriTek test \& histology & 91.0 \\
\hline & & & $\mathrm{R}^{*} \mathrm{AC}$ & 45 & 10 & PyloriTek test \& histology & 96.0 \\
\hline $\mathrm{Hai}^{59}$ & North & 2002 & EAC & 53 & 10 & CLO test \& histology & 98.1 \\
\hline \multirow[t]{3}{*}{ Vinh et al. ${ }^{60}$} & \multirow[t]{3}{*}{ North } & \multirow[t]{3}{*}{2003} & OAC & 59 & 7 & PyloriTek test \& histology & 91.7 \\
\hline & & & OAM & 57 & 7 & PyloriTek test \& histology & 73.9 \\
\hline & & & OMC & 58 & 7 & PyloriTek test \& histology & 82.2 \\
\hline Duat et al. ${ }^{56}$ & North & 2007 & PAC & 106 & 7 & CLO test & 95.8 \\
\hline Tiep et al. ${ }^{61}$ & North & 2008 & RAC & 36 & 7 & CLO test \& histology & 91.6 \\
\hline \multirow[t]{2}{*}{ Thang $^{57}$} & \multirow[t]{2}{*}{ North } & \multirow[t]{2}{*}{2010} & EAC & 30 & 7 & CLO test & 90.0 \\
\hline & & & EAC & 30 & 7 & CLO test & 93.3 \\
\hline $\operatorname{Vinh}^{62}$ & North & 2014 & EAC & 162 & 10 & HpFast test \& histology & 67.9 \\
\hline Huong and Thang ${ }^{63}$ & Central & 2007 & EAC & 77 & 7 & CLO test \& histology & 90.0 \\
\hline Nho et al. ${ }^{64}$ & Central & 2011 & EAC & 72 & 14 & CLO test \& histology & 84.7 \\
\hline \multirow[t]{2}{*}{ Ngoi $^{65}$} & \multirow[t]{2}{*}{ South } & \multirow[t]{2}{*}{2009} & $\mathrm{OAC}$ & 35 & 14 & CLO test \& histology & 68.5 \\
\hline & & & OAL & 35 & 14 & CLO test \& histology & 88.2 \\
\hline \multirow[t]{2}{*}{ Trung et al..$^{5}$} & \multirow[t]{2}{*}{ South } & \multirow[t]{2}{*}{2009} & EAC & 43 & 7 & CLO test \& UBT & 68.3 \\
\hline & & & EAL & 38 & 10 & CLO test \& UBT & 70.2 \\
\hline Hoang $^{66}$ & South & 2011 & PAC & 80 & 10 & CLO test \& histology & 62.8 \\
\hline
\end{tabular}

A, amoxicillin; C, clarithromycin; E, esomeprazole; M, metronidazole; L, levofloxacin; R, rabeprazole; P, pantoprazole; O, omeprazole; R*, ranitidine bismuth citrate; CLO test, campylobacter-like organism test; UBT, urease breath test. 
Table 2. Results of Helicobacter pylori Eradication by the Second Treatment Regimen in Vietnam

\begin{tabular}{|c|c|c|c|c|c|c|c|}
\hline Author & Local & Year & Regimens & Patient (n) & Time (day) & Methods & H. pylori eradication rate \\
\hline \multirow[t]{2}{*}{ Trung et al. $^{70}$} & South & 2008 & EAL & 19 & 10 & CLO test \& UBT & 58.8 \\
\hline & & & EBMT & 26 & 14 & CLO test \& UBT & 95.7 \\
\hline \multirow[t]{2}{*}{$\operatorname{Vinh}^{71}$} & North & 2011 & EAC & 31 & 10 & PyloriTek test \& histology & 80.7 \\
\hline & & & EBMT & 45 & 14 & PyloriTek test \& histology & 86.7 \\
\hline Hue et al. ${ }^{72}$ & South & 2016 & EBMT & 166 & 10 & E-test \& histology & 89.3 \\
\hline Di and Thang ${ }^{73}$ & Central & 2012 & EAL & 101 & 10 & CLO test \& histology & 83.2 \\
\hline Thang and $\mathrm{Anh}^{74}$ & Central & 2015 & RLTi & 59 & 7 & CLO test \& histology & 86.3 \\
\hline
\end{tabular}

A, amoxicillin; B, bismuth; C, clarithromycin; E, esomeprazole; M, metronidazole; L, levofloxacin; R, rabeprazole; T, tetracycline; Ti, tinidazole; UBT, urea breath test; CLO test, campylobacter-like organism test.

Table 3. Rate of Primary Antibiotic Resistance of Helicobacter pylori in Vietnam (2001-2016)

\begin{tabular}{|c|c|c|c|c|c|c|c|c|}
\hline \multirow{2}{*}{ Author/strains (n) } & \multirow{2}{*}{ Year/local } & \multirow{2}{*}{ Method } & \multicolumn{6}{|c|}{ Primary antibiotics resistance (\%) } \\
\hline & & & A & $\mathrm{C}$ & M & $\mathrm{L}$ & Te & Multidrug resistance* \\
\hline $\operatorname{Hoan}^{75}(\mathrm{n}=152)$ & 2001/North & $\mathrm{ADM}$ & 0 & 0 & 38.1 & & 5.8 & \\
\hline $\operatorname{Vinh}^{76}(\mathrm{n}=178)$ & 2003/North & E-test \& ADM & 18.1 & 21.6 & 54.3 & & & \\
\hline Nhan and $\mathrm{Mai}^{77}(\mathrm{n}=69)$ & 2006/South & ADM & 0 & 38.5 & 50.8 & & 9.2 & \\
\hline Thinh et al. ${ }^{78}(n=73)$ & 2009/North & DDM & 33.9 & 21.4 & 94.6 & & 21.4 & \\
\hline Nguyet and $\operatorname{Hanh}^{79}(\mathrm{n}=98)$ & 2010/North & DDM & 35.5 & 26.7 & 95.5 & & 17.8 & \\
\hline Toan et al. ${ }^{80}(\mathrm{n}=172)$ & 2012/North & DDM & 43.6 & 36.6 & 94.2 & & 20.9 & 56.4 \\
\hline Binh et $a l^{33}(n=103)$ & $2013^{\dagger}$ & E-test & 0 & 33.0 & 69.9 & 18.4 & 5.8 & 24.3 \\
\hline Dung et al. ${ }^{16}(n=220)$ & $2015^{\ddagger}$ & ADM & 7.7 & 43.6 & 83.6 & 33.2 & 10.9 & 58.2 \\
\hline Phan et al. ${ }^{34}(n=73)$ & 2015/Central & E-test & 0 & 34.2 & 75.3 & 35.6 & & 50.7 \\
\hline Quek et al..$^{35}(n=193)$ & 2016/South & E-test & 10.4 & 85.5 & 37.8 & 24.4 & & \\
\hline Mean & & & 14.9 & 34.1 & 69.4 & 27.9 & 17.9 & 47.4 \\
\hline
\end{tabular}

A, amoxicillin; C, clarithromycin; M, metronidazole; L, levofloxacin; Te, tetracycline; ADM, agar dilution method; E-test, Epsilometer test; DDM, disk diffusion method. E-test ${ }^{33}$ (AB Biodisk, Solna, Sweden), E-test ${ }^{34}$ (bioMerieux, Marcy I'Etoile, France), E-test ${ }^{35}$ (bioMerieux).

${ }^{*}$ Multidrug resistance: includes resistance to at least two antibiotics; ${ }^{\dagger}$ North Vietnam + South Vietnam; ${ }^{\ddagger}$ North Vietnam + Central Vietnam + South Vietnam.

with EBMT (96.7\%) than with EAC (80.7\%) (p<0.05). However, EBMT therapy had more side-effects (46.7\%) than EAC therapy (12.3\%). Hue et $a .^{72}$ found that the efficacy of eradication of $H$. pylori by EBMT was 89.3\%. However, in this study, the number of patients with moderate, severe and severe adverse events was $19.88 \%, 0.60 \%$ and $1.81 \%$, respectively. Other two studies using the triple therapy with levofloxacin had the rate of $H$. pylori eradication of over $80 \% .^{73,74}$ These results indicate that the therapeutic effect of levofloxacin in the rescue regimen is low and is associated with $H$. pylori resistance.

These results show that primary and secondary antibiotic resistance of $H$. pylori in Vietnam has increased over time, especially for clarithromycin and metronidazole. However, limitations in our study that the number of studies is small, intermittent and use classic methods (RUT, endoscopy and histology) to detect $H$. pylori. Therefore, there should be many more studies, in many different centers and longer duration.

\section{ANTIBIOTIC RESISTANCE OF H. PYLORI IN VIETNAM}

\section{Prevalence of primary antibiotic resistance of $\boldsymbol{H}$. pylori from 2001 to 2016}

There are many factors that affect efficiency of $H$. pylori eradication therapies such as patient's compliance, doses, quality of drugs, combined diseases, etc. Among those factors, the emergence of antibiotic-resistant $H$. pylori strains have been implicated as highest risk of treatment failure. The antibiotic resistance to $H$. pylori is divided into two types: primary antibiotic resistance and secondary antibiotic resistance.

There are two methods for detecting $H$. pylori resistance, including resistance to phenotypic resistance and genotype resistance. Phenotypic methods are applied in Vietnam since 2000. The methods include agar dilution method, disk dilution method and Epsilometer test. Method of detecting $H$. pylori genotype resistance has only been applied in recent years.

Table 3 presents the rate of primary antibiotic resistance to $H$. 
pylori in Vietnam from 2001 to 2016 period (16 years). ${ }^{16,33-35,75-80}$ Ten studies (three papers in English and seven papers in Vietnamese) were included in this review. A total of 308, 412, 523, 408, 399, and $268 \mathrm{H}$. pylori strains were included in this review to evaluate the prevalence of $H$. pylori primary resistance to amoxicillin, clarithromycin, metronidazole, levofloxacin, tetracycline, and multidrug resistance, respectively. Overall, the primary resistance rates of amoxicillin, clarithromycin, metronidazole, levofloxacin, tetracycline, and multidrug resistance were 15.0\%, 34.1\%, 69.4\%, 27.9\%, 17.9\%, and 48.8\%, respectively. Here, we also analyze in detail the rate of $H$. pylori resistance to the most commonly used antibiotics in $H$. pylori treatment in Vietnam. Fig. 2. shows the average rate of primary resistance of $H$. pylori with amoxicillin, clarithromycin, metronidazole, levofloxacin, and tetracycline in Vietnam during 16 years (from 2001 to 2016).

\section{Prevalence of secondary antibiotic resistance of $\boldsymbol{H}$. pylori from 2001 to 2016}

Studies on secondary resistance of $H$. pylori in Vietnam have been less published. From 2014 to 2016, three studies have been published (two papers in Vietnamese and one paper in Eng-

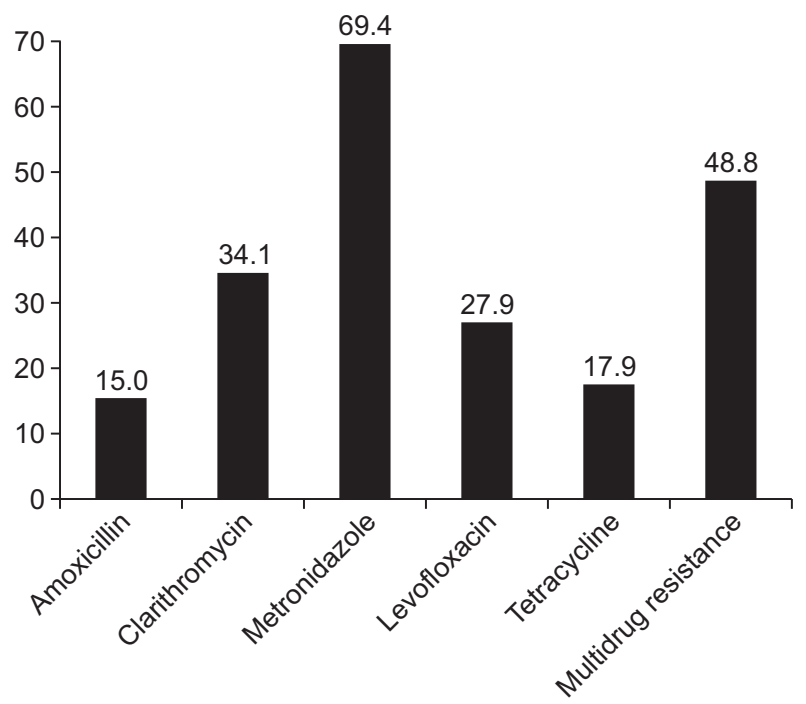

Fig. 2. Average rate of primary resistance with Helicobacter pylori in Vietnam from 2001 to 2016. lish). ${ }^{34,81,82}$ These studies only in central and Southern Vietnamwhere the rate of primary drug resistance tends to increase. Table 4 presents the rate of secondary antibiotic resistance to $H$. pylori in Vietnam trends in clarithromycin, levofloxacin and multiple drug resistance in Southern Vietnam are likely to increase over time. Minh and Hoang ${ }^{81}$ studied the rate of secondary resistance to $H$. pylori in 102 patients who failed treatment (at least one time). Research results showed that the secondary resistance rates of amoxicillin, clarithromycin, metronidazole, levofloxacin and tetracycline were 13.7\%, 56.9\%, 44.1\%, 25.5\%, and $23.5 \%$, respectively. Hue ${ }^{82}$ showed that secondary rates of resistance to clarithromycin, levofloxacin and multidrug were 94.3\%, 48.6\%, and 45.7\%, respectively.

In Central Vietnam, the secondary resistance rates of clarithromycin and levofloxacin are also likely to increase. Phan et al. ${ }^{34}$ showed that secondary rates of resistance to amoxicillin, clarithromycin, metronidazole, levofloxacin and multidrug were 5.3\%, 73.7\%, 78.9\%, 63.2\%, and 78.9\%, respectively.

Overall, the secondary resistance rates of amoxicillin, clarithromycin, metronidazole, levofloxacin, tetracycline, and multidrug resistance were 9.5\%, 74.9\%, 61.5\%, 45.7\%, 23.5\%, and $62.3 \%$, respectively.

Today, antibiotic resistance of $H$. pylori has become more serious and affect the outcome of treatment. The prevalence of bacterial resistance varies in different geographic areas and appears to be increasing with time in many countries. The European multicenter study group included 2,204 patients from 2008 to 2009, spanning 18 European countries and demonstrated $H$. pylori resistance rates to clarithromycin, metronidazole and levofloxacin at 17.5\%, 34.9\%, and 14.1\% respectively. ${ }^{83}$

Recently, Kuo et al.$^{84}$ have reviewed the system and metaanalysis of primary antibiotic resistance to $H$. pylori and the efficacy of first-line regimens in the Asia-Pacific region. The overall mean prevalence of primary $H$. pylori resistance were $17 \%$ (95\% CI, 15\% to 18\%) for clarithromycin, 44\% (95\% CI, $39 \%$ to $48 \%$ ) for metronidazole, $18 \%$ (95\% CI, $15 \%$ to $22 \%$ ) for levofloxacin, 3\% (95\% CI, 2\% to 5\%) for amoxicillin, and 4\% (95\% CI, 2\% to 5\%) for tetracycline. Prevalence of resistance to clarithromycin and levofloxacin rose significantly over time during the period investigated, whereas resistance to other antibiotics remained stable. In Vietnam, the prevalence of primary

Table 4. Rate of Secondary Antibiotic Resistance of Helicobacter pylori in Vietnam (2014-2016)

\begin{tabular}{|c|c|c|c|c|c|c|c|c|}
\hline \multirow{2}{*}{ Author/strains (n) } & \multirow{2}{*}{ Year/local } & \multirow{2}{*}{ Method } & \multicolumn{6}{|c|}{ Primary antibiotics resistance (\%) } \\
\hline & & & A & $\mathrm{C}$ & M & $\mathrm{L}$ & $\mathrm{Te}$ & Multidrug resistance* \\
\hline Minh et $a .^{81}(n=102)$ & 2014/South & $\mathrm{ADM}$ & 13.7 & 56.9 & 44.1 & 25.5 & 23.5 & - \\
\hline Phan et al. ${ }^{34}(\mathrm{n}=19)$ & 2015/Central & E-test & 5.3 & 73.7 & 78.9 & 63.2 & - & 78.9 \\
\hline $\mathrm{Hue}^{82}(\mathrm{n}=35)$ & 2016/South & E-test & - & 94.3 & - & 48.6 & - & $45.7^{\dagger}$ \\
\hline Mean & & & 9.5 & 74.9 & 61.5 & 45.7 & 23.5 & 62.3 \\
\hline
\end{tabular}

A, amoxicillin; C, clarithromycin; M, metronidazole; L, levofloxacin; Te, tetracycline; ADM, agar dilution method; E-test, Epsilometer test.

${ }^{*}$ Multidrug resistance: includes resistance to at least two antibiotics; ${ }^{\dagger}$ Clarithromycin+levofloxacin. 
resistance of $H$. pylori with clarithromycin and metronidazole was $34.0 \%$ and $72.0 \%$, respectively, and it was ranked second (after Pakistan). ${ }^{85}$

In Korea, Lee et al. ${ }^{85}$ studied the prevalence of primary and secondary resistance of $H$. pylori in 347 patients during 2003 to 2012. The study results showed that the prevalence of primary resistance of $H$. pylori increases for amoxicillin (6.3\% to 14.9\%, $\mathrm{p}=0.051)$, clarithromycin (17.2\% to $23.7 \%, \mathrm{p}=0.323)$ and both of levofloxacin and moxifloxacin (4.7\% to $28.1 \%$, $p=0.002$ ). Secondary resistance rate significantly increased in metronidazole, levofloxacin and moxifloxacin. ${ }^{85}$

\section{Primary and secondary clarithromycin resistance of $\boldsymbol{H}$. pylori in Vietnam}

Because clarithromycin is the most potent antibiotic involved in the management of $H$. pylori infections, resistance to clarithromycin is important. ${ }^{86,87}$ In European regions, ${ }^{88}$ the lowest clarithromycin resistance was reported from Norway (5.9\%), whilst the highest in Spain (32.01\%) and Portugal (42.35\%). European studies performed at the past 6 years intervals reported that $H$. pylori resistance decreased from 36.65\% in 2009 to 24.38\% in 2014. In Asian, mean overall prevalence of resistance to clarithromycin was $17 \%$ (95\% CI, $15 \%$ to $18 \%$ ), ranging from 0\% in Bhutan and Myanmar to 34\% in Vietnam and 37\% in Pakistan. ${ }^{84}$

In Vietnam, clarithromycin is the first line antibiotic selected in the triple therapy for $H$. pylori eradication treatment. Table 3 shows the proportion of primary resistance clarithromycin according to various studies..$^{16,33-35,75-80}$ Rate of primary resistance to clarithromycin ranged from $21.4 \%$ to $85.5 \%$. Therefore, clarithromycin resistance has increased, especially in the studies in the South Vietnam. ${ }^{35}$ In the North Vietnam, clarithromycin resistance had trended to further increase from 18.5\% in 2013 to $42.1 \%$ in 2015 (Table 5). ${ }^{16}$

The patients with the primary clarithromycin resistance will

Table 5. Rate of Antibiotic Resistance of Helicobacter pylori in Hanoi and Ho Chi Minh City-Vietnam

\begin{tabular}{llcc}
\hline Local & \multicolumn{1}{c}{ Antibiotic } & $\begin{array}{c}\text { Binh et al. } \\
(2013)^{33}\end{array}$ & $\begin{array}{c}\text { Dung et al. } \\
(2015)^{16}\end{array}$ \\
\hline Hanoi & Amoxicillin (A) & 0 & 3.9 \\
& Clarithromycin (C) & 18.5 & 42.1 \\
& Metronidazole (M) & 70.3 & 89.5 \\
& Levofloxacin (L) & 18.5 & 21.1 \\
& Tetracycline (Te) & 7.4 & 11.8 \\
Ho Chi Minh City & Amoxicillin (A) & 0 & 6.9 \\
& Clarithromycin (C) & 49.0 & 39.2 \\
& Metronidazole (M) & 69.3 & 81.4 \\
& Levofloxacin (L) & 18.3 & 41.2 \\
& Tetracycline (Te) & 4.0 & 12.7 \\
\hline
\end{tabular}

Data are presented as percentage. have risk of the secondary resistance. For the 2006 to 2008 period, a study in the South of Poland found that the primary clarithromycin resistance was $21 \%$ and the secondary resistance was $80 \% .^{89}$ In Thailand, in 2009, there was a report on rate of the primary resistance after treatment of $78.7 \%$, compared to the secondary resistance of $10.6 \%{ }^{90}$

In Vietnam, in 2003, Vinh $^{76}$ found that the rate of clarithromycin resistance was 21.6\% before treatment and 78.9\% after treatment. Minh and Hoang ${ }^{81}$ found that the rate of clarithromycin resistance after 1,2 and 3 treatments was incremental and 44.0\%; 66.7\% and 83.6\%, respectively (Table 4). Phan et $a l^{34}$ indicated very high rate of the primary and secondary clarithromycin resistance: $34.2 \%$ and $73.7 \%$, respectively $(\mathrm{p}<0.05)$. The rate of primary and secondary resistance of $H$. pylori to clarithromycin has increased, affecting the therapeutic effect. The Maastricht III guidelines on $H$. pylori infection management recommend substituting metronidazole for clarithromycin when resistance to this antibiotic exceeds $15 \%$ to $20 \%$. $^{20}$

\section{Primary and secondary amoxicillin resistance of $\boldsymbol{H}$. pylori in Vietnam}

Resistance to amoxicillin has been shown to be negligible ( 0 to $<2 \%$ ) in European countries, such as Germany and the Netherlands. ${ }^{91}$ In Asia, mean overall prevalence of resistance to amoxicillin was 3\% (95\% CI, 21\% to 34\%). ${ }^{84}$

In Vietnam, amoxicillin is used in the triple therapy or the quadruple therapy for $H$. pylori eradication. The rate of the primary amoxicillin resistance varies in different times and studies: from $0 \%$ to $43.6 \%$ (Table 3). ${ }^{33,77,80}$ The rate of the primary amoxicillin resistance in the North Vietnam has trended to further increase (18.1\% to $43.6 \%)^{76,78-80}$ than in the South Vietnam (0\% to $10.4 \%$ ) (Table 3). ${ }^{16,33-35,77}$

$\mathrm{Vinh}^{76}$ found that the rate of the secondary resistance of amoxicillin was 36.8\%. Minh and Hoang ${ }^{81}$ found that the rate of the secondary amoxicillin resistance after 1, 2 and 3 treatments was 13.6\%, 16.7\%, and 0\% (Table 4). Secondary resistance rates of amoxicillin in Southern Vietnam are lower than in the North Vietnam. Because of amoxicillin resistance rate is not high, so amoxicillin still used for $H$. pylori eradication in Vietnam.

\section{Primary and secondary metronidazole resistance of $\boldsymbol{H}$. pylori in Vietnam}

Metronidazole in order to eradicate this bacterium, has been widely used in combination therapies such as metronidazolebased triple therapy, concomitant therapy and bismuth-containing quadruple therapy. Metronidazole resistance is the most common antibiotic resistance in $H$. pylori and overall metronidazole resistance found in $47.22 \%$ in descending order in Africa 75.02\%, South America 52.85\%, Asia 46.57\%, Europe 31.19\%, to $30.5 \%$ in North America. ${ }^{88}$ In Asia, mean overall prevalence of resistance to metronidazole was 44\% (95\% CI, 39\% to 48\%) ranging from $10 \%$ in Japan to $84 \%$ in Bangladesh and $88 \%$ in 
Nepan. $^{84}$

In the 1990s, metronidazole was early used in H. pylori eradication regimen and used in the North Vietnam more than in the South Vietnam. Primary resistance rate of metronidazole from: $37.8 \%{ }^{35}$ to $95.5 \% .^{77}$ The rate of the primary metronidazole resistance in the North Vietnam increased (38.1\% to 95.5\%) ${ }^{75,79}$ higher than that in the South Vietnam (37.8\% to 50.8\%) (Table 3). ${ }^{35,77}$ The rate of the primary metronidazole resistance has increased by time. In Hanoi, the rate of the primary metronidazole resistance increased from 70.3\% in 2013 to 89.5\% in 2015 (Table 5). In Ho Chi Minh City, the rate of the primary metronidazole resistance increased from 69.3\% in 2013 to 81.4\% in 2015 (Table 5). ${ }^{16,33}$

Metronidazole is used frequently to treat not only $H$. pylori infection but also other infections such as intestinal parasites, periodontal, and gynecological diseases, which are common in developing countries, including Vietnam. ${ }^{26}$ Because the drug has many side-effects, causing tiredness for the patients and high rate of resistance, metronidazole has not been used in the regimen of $H$. pylori eradication in Vietnam. ${ }^{67}$

\section{Primary and secondary tetracycline resistance of $\boldsymbol{H}$. py lori in Vietnam}

In the world, the rate of tetracycline resistance is low, especially in the developed countries. ${ }^{90}$ In Asia and Africa, tetracycline and bismuth are used more than in Europe and the America. ${ }^{84,88}$ The total rate of tetracycline resistance did not vary in South America and North America (the resistance was absent), whilst it was relatively high in Africa (50\%). In Asia, the resistance was absent in Thailand, and very low in China (0.6\%) and South Korea (0.01\%). In contrast, increased values were found in India (53.8\%), and Iran (11.7\%). The prevalence of tetracycline resistance stays very low (less than 7.4\%) in almost parts of the world except for Africa. ${ }^{88}$ The comparison of data showed that tetracycline resistance was decreasing in the world, 26.85\% in 2009 to $6.11 \%$ in $2014 .^{88}$

In Vietnam (see Table 5), the primary tetracycline resistance ranges $5.8 \%$ to $21.4 \%$ (Table 3). Minh and Hoang ${ }^{81}$ found that the rate of the secondary tetracycline resistance after 1, 2, and 3 treatments (Table 4) was 19.7\%, 30.0\%, and 33.3\%, respectively. So far, the research and use of tetracycline for the eradication of $H$. pylori in Vietnam is very limited.

\section{Primary and secondary levofloxacin resistance of $\boldsymbol{H}$. pylori in Vietnam}

Many studies have examined levofloxacin-PPI as a first-line therapy for eradication of $H$. pylori infection. ${ }^{92,93}$ However, the eradication rates achieved with first-line levofloxacin-based treatments are not uniform. Some reports show the improved efficacy with levofloxacin-based regimens in comparison to standard first-line therapy, whereas others have found equivalent or poorer responses. ${ }^{94,95}$ The European recommendation only uses levofloxacin in the rescue regimen, when the results of antibiotic therapy are available. ${ }^{20}$ When first-line therapy fails, the Maastricht IV Consensus Report recommends that bismuthcontaining quadruple therapy can be a choice for second-line therapy. ${ }^{8}$ Many studies have investigated levofloxacin based regimens as second-line treatments, including meta analyses. ${ }^{96}$

Generally, resistance to levofloxacin is low ( $<19 \%$ ) worldwide. The rate of the primary levofloxacin resistance varies in the world's regions and increases in Asian (25.28\%) and South America (21.23\%) higher than that in Africa and Europe $(<15 \%)$. In Asia, the rate of levofloxacin resistance also varies in different countries: Japan (57\%), Korea (24.55\%), Iran (5.3\%), and Malaysia $(2.6 \%)^{88}$

In Vietnam, a majority of the studies focused in the South Vietnam $^{16,33-35}$ and their results indicated that the rate of the primary levofloxacin resistance ranged from $18.4 \%$ to 35.6\% (Table $3)$. The rate of the primary levofloxacin resistance increased from 18.3\% in 2013 to $41.2 \%$ in 2015 in Ho Chi Minh City (Table 5). ${ }^{16,33}$ The rates of the secondary levofloxacin resistance after 1 , 2 and 3 treatments were 25.7\%, 23.3\%, and 33.3\% respectively (Table 4). ${ }^{81}$ Phan et al. ${ }^{34}$ found that the rates of the primary and secondary levofloxacin resistance were very high and 35.6\% and $63.2 \%$, respectively $(\mathrm{p}<0.05)$. Other fluoroquinolones such as nalidixic acid, ciprofloxacin and ofloxacin, which are commonly used in Vietnam, may lead to cross resistance with levofloxacin. Because the rate of levofloxacin resistance increased, so levofloxacin is not used much in $H$. pylori eradication in Vietnam.

\section{Multidrug resistance patterns of $\boldsymbol{H}$. pylori in Vietnam}

Multidrug resistance has recently appeared as a serious challenge in the fight against infections in over the world. $H$. pylori strains harboring triple or quadruple resistance can hinder the choice and success of the eradication regimen. Binh et al. ${ }^{33}$

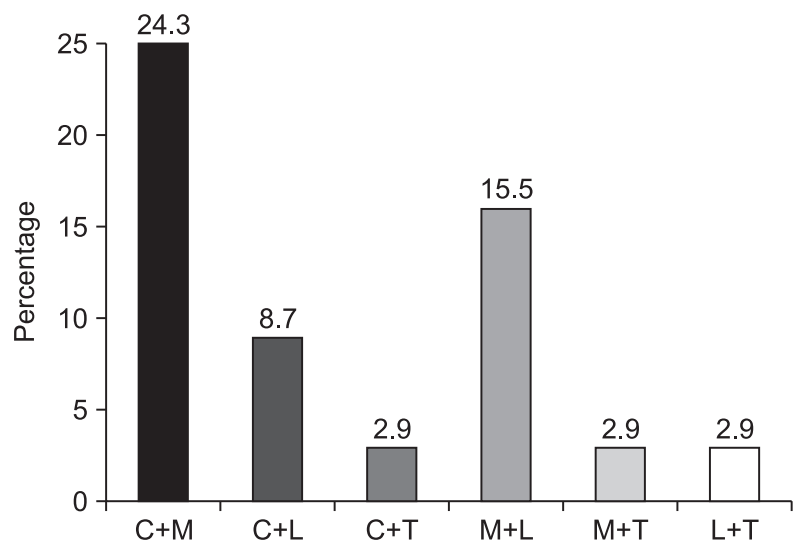

Fig. 3. Multidrug resistance patterns of Helicobacter pylori in Vietnam. $\mathrm{C}+\mathrm{M}$, clarithromycin+metronidazole; $\mathrm{C}+\mathrm{L}$, clarithromycin+levofloxacin; $\mathrm{C}+\mathrm{T}$, clarithromycin+tetracycline; $\mathrm{M}+\mathrm{L}$, metronidazole+levofloxacin; $\mathrm{M}+\mathrm{T}$, metronidazole+tetracycline; $\mathrm{L}+\mathrm{T}$, levofloxacin+ tetracycline. 
showed that 33\% (34 strains) of the isolates were the resistant to at least two antibiotics. Resistance to clarithromycin and metronidazole was most commonly observed (24.3\%), and this may be the main reason for failure of treatment in Vietnam. Fig. 3 presents the multidrug resistance of $H$. pylori in Vietnam.

\section{CAUSES OF ANTIBIOTIC RESISTANCE IN VIETNAM}

\section{Contributory factors}

The contributory factors to treatment failure are multidimensional and complex. Host genetic factors, $H$. pylori virulent factors, antibiotic-resistant $H$. pylori strains, smoking habits, compliance to therapy and duration of therapy affect totally treatment outcome. In Vietnam, Dung et al. ${ }^{16}$ found that some causes as follows: wide use of antibiotics, incorrect dosage, quality of antibiotic, noncompliance of treatment protocol, bad habits (alcohol and tobacco consumption), mutation of $H$. pylori.

In fact, arbitrary use antibiotics (without a prescription, increase dose arbitrarily) is a common problem in Vietnam and might leading to the development of new antibiotic-resistant $H$. pylori strains. In addition, bad habits such as alcohol, beer, smoking can also affect the effectiveness of $H$. pylori eradication.

Several studies have examined the relationship between risk factors and the frequency of primary and secondary resistance of $H$. pylori. Risk factors should be analyzed include: age, gender, history of previous eradication treatment, smoking, occupation, type of residence, etc. Lee et al. ${ }^{85}$ showed that "previous eradication" was an independent risk factor for the development of clarithromycin $(\mathrm{p}<0.001)$, azithromycin $(\mathrm{p}<0.001)$, levofloxacin $(p=0.003)$ and moxifloxacin $(p=0.006)$ resistance. District: "rural area" was an independent risk factor for the development of azithromycin ( $p=0.049$ ) resistance. Job: "no occupation" was an independent risk factor for the development of azithromycin $(p=0.034)$ resistance. However, other risk factors (gender, disease, alcohol, smoking, and socioeconomic) was not related to antimicrobial resistance of $H$. pylori.

In Vietnam, there are very few studies on the risk factors associated with $H$. pylori resistance. Recently, Hue ${ }^{82}$ studied the relationship between risk factors and $H$. pylori resistance. Re- search results showed that "age $\geq 30$ " and "previous eradication" was an independent risk factor for the development of clarithromycin. However, no correlation was found with levofloxacin (Table 6).

\section{Gene mutation of $\boldsymbol{H}$. pylori related to antibiotic resis- tance}

Two techniques applied clinically to define the antibiotic resistance to $H$. pylori comprise $H$. pylori culture and resistance regimen.$^{97}$ However, culturing $H$. pylori bacteria is very difficult, obtains low positive rate and requires long time; and not establishments can do it. To add these methods, at present, gene mutation of $H$. pylori bacteria with different antibiotics is defined. In Vietnam, initial studies of gene mutation of $H$. pylori bacteria related to antibiotic resistance (clarithromycin and levofloxacin) have been conducted. ${ }^{98-102}$ There are a total of five studies of gene mutation of $H$. pylori bacteria related to antibiotic resistance (one study in the North Vietnam, ${ }^{98}$ two studies in the Central Vietnam, ${ }^{77,78,102}$ and two studies in the South Vietnam ${ }^{35,100}$ ).

Toan et al. ${ }^{98}$ showed two types of gene mutation in two positions detected: A2143G (26.7\%), A2143T (6.7\%), and T2182C (80.0\%). Two types of gene mutation combined on a patient were $\mathrm{A} 2143 \mathrm{G}+\mathrm{T} 2182 \mathrm{C}$ and $\mathrm{A} 2143 \mathrm{~T}+\mathrm{T} 2182$ at the respective rates of $13.3 \%$ and $6.7 \%$.

Phan et al. ${ }^{34}$ studied gene mutation of $H$. pylori bacteria with clarithromycin and levofloxacin in Hue (Central Vietnam). Study results pointed that the mutation rate of A2143G was 85.7\% (30/35) in the strain of bacteria resisted to clarithromycin. Similarly, the study of Doanh et al. ${ }^{102}$ also showed the mutation rate of A2143G was very high: 40 out of 41 (97.6\%).

Trung et al. ${ }^{100}$ studied gene mutation on 30 strains of $H$. pylori bacteria resisted to clarithromycin and 31 strains of $H$. pylori bacteria resisted to levofloxacin. Study results indicated 96.7\% strains of $H$. pylori bacteria mutated with clarithromycin and $54.8 \%$ strains of $H$. pylori bacteria mutated with. The mutation rate with clarithromycin and levofloxacin was 56.7\%.

However, gene mutation of $H$. pylori bacteria with clarithromycin in Vietnam is a controversy. ${ }^{102}$ While continuously studying situation and causes of the antibiotic resistance to $H$. pylori, applying the latest consensus (Maastricht V/Toronto) is extremely necessary. Selection of the regimens, combination of

Table 6. Multivariate Analysis of Predictors for Helicobacter pylori Resistance

\begin{tabular}{cllc}
\hline Antibiotic & Parameter & & Multivariate analysis \\
\cline { 2 - 4 } Clarithromycin $(\mathrm{n}=153)$ & & OR (95\% CI) & p-value \\
\hline Levofloxacin $(\mathrm{n}=154)$ & Age $\geq 30 \mathrm{yr}$ & $3.2(1.3-7.7)$ & $7.7(1.7-34.7)$ \\
& Previous eradication & $1.9(0.9-3.7)$ & 0.008 \\
\hline
\end{tabular}

OR, odds ratio; CI, confidence interval. 
Table 7. Helicobacter pylori Eradication Regimens in Vietnam ${ }^{45}$

\begin{tabular}{llc}
\hline & \multicolumn{1}{c}{ Regimen } & $\begin{array}{c}\text { Duration of } \\
\text { therapy }\end{array}$ \\
\hline Triple therapy & PPI+A+C & 7 Days \\
Sequential therapy & First 5 days: PPI+A & 5 Days \\
& Next 5 days: PPI+C+Ti & 5 Days \\
Concomitant therapy & PPI+A+C+M/Ti & 10 Days \\
Bismuth quadruple therapy & PPI+M+Te+B & 14 Days \\
\hline
\end{tabular}

PPI, proton pump inhibitor; A, amoxicillin; C, clarithromycin; Ti, tinidazole; M, metronidazole; Te, tetracycline; $\mathrm{B}$, bismuth.

PPI doses and time, and $H$. pylori tests (culture, PCR and study of gene mutation of $H$. pylori) plays an importance role for efficiency of $H$. pylori eradication.

\section{PERSPECTIVES FROM VIETNAM ASSOCIATION OF GAS- TROENTEROLOGY FOR DIAGNOSIS AND TREATMENT OF H. PYLORI INFECTION}

In Vietnam, from 1990 to 2010, triple therapy (PPI + combination of two antibiotics) was used clinically for eradication with H. pylori. However, after more than two decades, the antibiotic resistance to $H$. pylori has increased by time. Based on International Consensus (Maastricht IV) ${ }^{8}$ and based on the increasing resistance of $H$. pylori to antibiotics in Vietnam, Vietnam Association of Gastroenterology has established a consensus on $H$. pylori eradication (June 2012 in Ho Chi Minh City). ${ }^{67}$ The followings are some main contents related to $H$. pylori eradication: ${ }^{67}$ (1) treatment regimens and duration (Table 7); (2) provide treatment recommendations for areas with increased rates of resistance.

Recommendation 25: First-line therapy for $H$. pylori eradication: Because the rate of antibiotic resistance in the North Vietnam and the Central Vietnam is lower than that in the South Vietnam, the triple therapy (PPI+A+C for 10 to 14 days) is recommended to be applied in this region (grade of recommendation B; agreement: 76\%). In the South Vietnam, due to high rate of antibiotic resistance, sequential therapy regime or quadruple therapy (with/without bismuth) for $H$. pylori eradication (grade of recommendation B; agreement: 83\%). ${ }^{67}$

Recommendation 26: Second-line therapy for H. pylori eradication: (1) Use Bismuth quadruple therapy if it has not yet been used before (grade of recommendation A; agreement: 97\%). (2) Use $\mathrm{PPI}+\mathrm{A}+\mathrm{L}$ triple therapy if Bismuth quadruple therapy was used but unsuccessful (grade of recommendation A; agreement: 93\%). ${ }^{67}$

However, recent data indicate that primary and secondary resistance of $H$. pylori to clarithromycin, metronidazole and levofloxacin is increasing. ${ }^{33-35}$ This is of concern and suggests two important principles when prescribing a therapy in Vietnam: (1) clarithromycin-based or metronidazole-based triple therapy might not be useful as first-line therapies; (2) levofloxacinbased triple therapy should not be used as an alternative treatment. Therefore, first-line strategies such as bismuth-based quadruple or non-bismuth-based quadruple therapy should be recommended for Vietnamese infected patients.

In addition, it is necessary to apply techniques such as bacterial culture, antimicrobial susceptibility, gene mutation study of $H$. pylori is very necessary. The Maastricht V Consensus showed that treatment regimens for areas with clarithromycin resistance $>15 \%$ and $<15 \%$. ${ }^{69}$ Based on this, Vietnam Association of Gastroenterology needs to have a new consensus, to improve the effectiveness of $H$. pylori eradication in the future.

\section{CONCLUSIONS}

Vietnam has high rate of $H$. pylori infection in community as well as in gastric duodenal diseases (chronic gastritis, gastric ulcer, duodenal ulcer, and gastric cancer). In Vietnam, in early 1990s, rate of $H$. pylori eradication exceeded 90\%. But, recent statistics indicated that rate of $H$. pylori eradication has reduced to $60 \%-70 \%$ and related to antibiotic resistance of $H$. pylori. The rate of metronidazole, clarithromycin and levofloxacin resistance has been increasing. Application of the recommendations from the International Consensus (Maastricht V/Toronto) is extremely necessary to improve efficiency of $H$. pylori eradication.

\section{CONFLICTS OF INTEREST}

No potential conflict of interest relevant to this article was reported.

\section{REFERENCES}

1. Marshall BJ, Warren JR. Unidentified curved bacilli in the stomach of patients with gastritis and peptic ulceration. Lancet 1984;1:1311-1315.

2. Blaser MJ, Atherton JC. Helicobacter pylori persistence: biology and disease. J Clin Invest 2004;113:321-333.

3. Vakil N, Megraud F. Eradication therapy for Helicobacter pylori. Gastroenterology 2007;133:985-1001.

4. Fukase K, Kato M, Kikuchi S, et al. Effect of eradication of Helicobacter pylori on incidence of metachronous gastric carcinoma after endoscopic resection of early gastric cancer: an open-label, randomised controlled trial. Lancet 2008;372:392-397.

5. Dinis-Ribeiro M, Areia M, de Vries AC, et al. Management of precancerous conditions and lesions in the stomach (MAPS): guideline from the European Society of Gastrointestinal Endoscopy (ESGE), European Helicobacter Study Group (EHSG), European Society of Pathology (ESP), and the Sociedade Portuguesa de Endoscopia Digestiva (SPED). Endoscopy 2012;44:74-94.

6. Correa P. Gastric cancer: overview. Gastroenterol Clin North Am 
$2013 \cdot 42 \cdot 211-217$

7. Cao L, Yu J. Effect of helicobacter pylori infection on the composition of gastric microbiota in the development of gastric cancer. Gastrointest Tumors 2015;2:14-25.

8. Malfertheiner P, Megraud F, O'Morain CA, et al. Management of Helicobacter pylori infection: the Maastricht IV/ Florence Consensus Report. Gut 2012;61:646-664.

9. Banić M, Franceschi F, Babić Z, Gasbarrini A. Extragastric manifestations of Helicobacter pylori infection. Helicobacter 2012;17 Suppl 1:49-55.

10. Wroblewski LE, Peek RM Jr, Wilson KT. Helicobacter pylori and gastric cancer: factors that modulate disease risk. Clin Microbiol Rev 2010;23:713-739.

11. Hoang TT, Bengtsson C, Phung DC, Sörberg M, Granström M. Seroprevalence of Helicobacter pylori infection in urban and rural Vietnam. Clin Diagn Lab Immunol 2005;12:81-85.

12. Nguyen BV, Nguyen KG, Phung CD, et al. Prevalence of and factors associated with Helicobacter pylori infection in children in the north of Vietnam. Am J Trop Med Hyg 2006;74:536-539.

13. Nguyen VB, Nguyen GK, Phung DC, et al. Intra-familial transmission of Helicobacter pylori infection in children of households with multiple generations in Vietnam. Eur J Epidemiol 2006;21:459-463.

14. Nguyen TL, Uchida T, Tsukamoto Y, et al. Helicobacter pylori infection and gastroduodenal diseases in Vietnam: a crosssectional, hospital-based study. BMC Gastroenterol 2010;10:114.

15. Nguyen LT, Uchida T, Tsukamoto Y, et al. Evaluation of rapid urine test for the detection of Helicobacter pylori infection in the Vietnamese population. Dig Dis Sci 2010;55:89-93.

16. Dung HD, Binh TT, Khien VV, et al. The incidence of antibiotic resistance of Helicobacter pylori. Vietnamese J Gastroenterol 2015;6:830-836.

17. Shiota S, Yamaoka Y. Management of Helicobacter pylori. F1000 Med Rep 2010;2:20.

18. Hosking SW, Ling TK, Chung SC, et al. Duodenal ulcer healing by eradication of Helicobacter pylori without anti-acid treatment: randomised controlled trial. Lancet 1994;343:508-510.

19. Shiota S, Murakami K, Fujioka T, Yamaoka Y. Population-based strategies for Helicobacter pylori-associated disease management: a Japanese perspective. Expert Rev Gastroenterol Hepatol 2010;4:149-156

20. Malfertheiner P, Megraud F, O'Morain C, et al. Current concepts in the management of Helicobacter pylori infection: the Maastricht III Consensus Report. Gut 2007;56:772-781.

21. Takenaka R, Okada H, Kato J, et al. Helicobacter pylori eradication reduced the incidence of gastric cancer, especially of the intestinal type. Aliment Pharmacol Ther 2007;25:805-812.

22. Sugiyama T, Sakaki N, Kozawa H, et al. Pylori Forum Gastritis Study Group. Sensitivity of biopsy site in evaluating regression of gastric atrophy after Helicobacter pylori eradication treatment. Aliment Pharmacol Ther 2002;16 Suppl 2:187-190.

23. McColl KE. Clinical practice. Helicobacter pylori infection. N Eng
J Med 2010;362:1597-1604.

24. Jenks PJ. Causes of failure of eradication of Helicobacter pylori. BMJ 2002;325:3-4

25. Suzuki T, Matsuo K, Sawaki A, et al. Influence of smoking and CYP2C19 genotypes on $\mathrm{H}$. pylori eradication success. Epidemiol Infect 2007;135:171-176.

26. Mégraud F. H pylori antibiotic resistance: prevalence, importance, and advances in testing. Gut 2004;53:1374-1384.

27. Debets-Ossenkopp YJ, Herscheid AJ, Pot RG, Kuipers EJ, Kusters JG, Vandenbroucke-Grauls CM. Prevalence of Helicobacter pylori resistance to metronidazole, clarithromycin, amoxycillin, tetracycline and trovafloxacin in The Netherlands. J Antimicrob Chemother 1999;43:511-515.

28. van der Wouden EJ, van Zwet AA, Vosmaer GD, Oom JA, de Jong A, Kleibeuker JH. Rapid increase in the prevalence of metronidazole-resistant Helicobacter pylori in the Netherlands. Emerg Infect Dis 1997;3:385-389.

29. Mégraud F. Epidemiology and mechanism of antibiotic resistance in Helicobacter pylori. Gastroenterology 1998;115:1278-1282.

30. Broutet N, Tchamgoué S, Pereira E, Lamouliatte H, Salamon R, Mégraud F. Risk factors for failure of Helicobacter pylori therapy: results of an individual data analysis of 2751 patients. Aliment Pharmacol Ther 2003;17:99-109.

31. Wheeldon TU, Granström M, Hoang TT, Phuncarg DC, Nilsson LE, Sörberg M. The importance of the level of metronidazole resistance for the success of Helicobacter pylori eradication. Aliment Pharmacol Ther 2004;19:1315-1321.

32. Chey WD, Wong BC. American College of Gastroenterology guideline on the management of Helicobacter pylori infection. Am J Gastroenterol 2007;102:1808-1825.

33. Binh TT, Shiota S, Nguyen LT, et al. The incidence of primary antibiotic resistance of Helicobacter pylori in Vietnam. J Clin Gastroenterol 2013;47:233-238.

34. Phan TN, Santona A, Tran VH, et al. High rate of levofloxacin resistance in a background of clarithromycin- and metronidazoleresistant Helicobacter pylori in Vietnam. Int J Antimicrob Agents 2015;45:244-248.

35. Quek C, Pham ST, Tran KT, et al. Antimicrobial susceptibility and clarithromycin resistance patterns of Helicobacter pylori clinical isolates in Vietnam. F1000Res 2016;5:671.

36. Fock KM, Ang TL. Epidemiology of Helicobacter pylori infection and gastric cancer in Asia. J Gastroenterol Hepatol 2010;25:479486.

37. Graham DY, Adam E, Reddy GT, et al. Seroepidemiology of Helicobacter pylori infection in India. Comparison of developing and developed countries. Dig Dis Sci 1991;36:1084-1088.

38. Graham DY, Malaty HM, Evans DG, Evans DJ Jr, Klein PD, Adam E. Epidemiology of Helicobacter pylori in an asymptomatic population in the United States. Effect of age, race, and socioeconomic status. Gastroenterology 1991;100:1495-1501.

39. Asaka M, Kimura T, Kudo M, et al. Relationship of Helicobacter pylori to serum pepsinogens in an asymptomatic Japanese popu- 
lation. Gastroenterology 1992;102:760-766.

40. Quach DT, Hiyama T, Shimamoto F, et al. Value of a new sticktype rapid urine test for the diagnosis of Helicobacter pylori infection in the Vietnamese population. World J Gastroenterol 2014;20:5087-5091.

41. Binh TT, Tuan VP, Dung HDQ, et al. Molecular epidemiology of helicobacter pylori infection in a minor ethnic group of Vietnam: a multiethnic, population-based study. Int J Mol Sci 2018;19: E708.

42. Nguyen VB, Nguyen TA, Nguyen TV, Pham DP, Hoang TH, Phung DC. Epidemiology of Helicobacter pylori infection in Kinh and Khmer children in Mekong Delta, Vietnam. Ann Clin Lab Res 2015;S1:1-9.

43. Nguyen TV, Nguyen VB, Phan TT, Ha TT, Le TL, Phung DC. Epidemiology of Helicobacter pylori infection in Tay children in Vietnam. Ann Clin Lab Res 2016;4:125.

44. Nguyen TV, Phan TT, Nguyen VB, et al. Prevalence and risk factors of Helicobacter pylori infection in Muong children in Vietnam. Ann Clin Lab Res 2017;5:159.

45. Lim SH, Kwon JW, Kim N, et al. Prevalence and risk factors of Helicobacter pylori infection in Korea: nationwide multicenter study over 13 years. BMC Gastroenterol 2013;13:104.

46. Long T, Dung TT, Chung NQ, et al. The relationship between Helicobacter pylori infection and gastric cancer in Vietnamese patients: a cases control study. Vietnamese J Gastroenterol 2006;1:10-19.

47. Thang ND. Prevalence of Helicobacter pylori infection in patients with duodenal endoscopy at an Agricultural Hospital. Vietnamese J Gastroenterol 2007;2:339-343.

48. Thinh NV. Studies on Helicobacter pylori infection and mucosal lesions in patients with chronic gastritis [Ph.D. thesis]. $108 \mathrm{In}$ stitute of Clinical Medical and Pharmaceutical Sciences: Hanoi, 2010. p. 32-73.

49. Dung HD. Study on the relationship between cagA, vacA of Helicobacter pylori, gastrin concentration, pepsinogen and histopatholog0y in patients with chronic gastritis [Ph.D. thesis]. 108 Institute of Clinical Medical and Pharmaceutical Sciences: Hanoi, 2012. p. 22-67.

50. Long T. Gastro-duodenal disease and Helicobacter pylori bacteria. Hanoi: Medical Publishing House, 2003.

51. Huong PT. Study on the status of Helicobacter pylori infection and treatment response in patients with gastro-duodenal ulcer at Hue central hospital in 1998-1999 [master's thesis]. Hue College of Medicine and Pharmacy: Hue, 1999. p. 17-54.

52. Hop TV, Tho LT. Incidence of Helicobacter pylori infection in gastric cancer patients in Hanoi city and rural neighborily areas. Vietnamese J Gastroenterol 2008;3:579-585.

53. Binh TT, Tuan VP, Dung HDQ, et al. Advanced non-cardia gastric cancer and Helicobacter pylori infection in Vietnam. Gut Pathog 2017;9:46

54. Lam SK, Talley NJ. Report of the 1997 Asia Pacific Consensus Conference on the management of Helicobacter pylori infection.
J Gastroenterol Hepatol 1998;13:1-12.

55. Trung TT, Hai DT, Duc QT, et al. Effectiveness of EAC and EAL first-line regimens for H. pylori eradication. J Med Hochiminh City 2009;13:5-10.

56. Duat NQ, Son NT, Tu TV, et al. Initially studied the fluctuation of anti-H. pylori antibodies before and after treatment with Pantoprazole + Amoxicillin + Clarithromycin. J Pract Med 2007;2:612.

57. Thang ND. Results of treatment in Helicobacter pylori gastric ulcer with Esomeprazole-Amoxicillin-Clarithromycin (EAC) regimen lasted 1 and 2 weeks. Clin Med Bachmai Hosp 2010;53:3943.

58. Mao HV, Lak BV, Long T, et al. Omeprazole or ranitidine bismuth citrate triple therapy to treat Helicobacter pylori infection: a randomized, controlled trial in Vietnamese patients with duodenal ulcer. Aliment Pharmacol Ther 2000;14:97-101.

59. Hai TT. Results of treatment of duodenal ulcer with $\mathrm{H}$. pylori infection by Nexium + Amoxicillin + Clarithromycin, follow up after 6 months [master's thesis]. Hanoi Medical University: Hanoi, 2002. p. $19-45$.

60. Vinh NT, Hop TV, Mao HV, et al. The effectiveness of twice-daily first line therapy (OAC, OAM, OMC) and the second line therapies (OAC, OBMT) for patients with Helicobacter pylori positive gastro-duodenal ulcer. 4th Congress on Gastroenterology of Southeast Asian Nations. Vietnamese J Gastroenterol 2003;2:328-332.

61. Tiep TH, Dung TT, Hoa LD, et al. A study on assessing results of triple therapy using rabeprazole combined with amoxicillin and clarithromycin in peptic ulcer patients infected with Helicobacter pylori. Vietnamese J Gastroenterol 2008;3:10-19.

62. Vinh NT. Study on the antimicrobial resistance of Helicobacter pylori and the efficacy of Esomeprazole-Amoxicillin-Clarithromycin in the treatment of patients with duodenal ulcer. Scientific Research, Ministry of Health, 2014.

63. Huong PT, Thang HT. Study on the efficacy of combination therapy with Esomeprazole + Clarithromycine + Amoxicillin in the treatment of gastric and duodenal ulcer with Helicobacter pylori infection. Vietnamese J Gastroenterol 2007;5:279-283.

64. Nho LV, Thang HT, Huy TV. Effective study regimen Amoxicillin + Clarithromycin Esomeprazole + in patients with duodenal ulcer with H. pylori-positive. J Vietnamese Med 2011;Suppl:147-153.

65. Ngoi DH. Comparison of the regimen: Omeprazole + Amoxicillin + Levofloxacin versus Omeprazole + Amoxicillin + Clarithomycin for Helicobacter pylori eradication in patients with peptic ulcer disease [master's thesis]. HCMC University of Medicine and Pharmacy: Ho Chi Minh City, 2009. p. 12-55.

66. Hoang BH. Efficacy of sequential regimens for the eradication of Helicobacter pylori in patients with peptic ulcer disease. J Med Hochiminh City 2011;15:303-307.

67. The Vietnam Association of Gastroenterology. Consensus on the diagnosis and treatment of Helicobacter pylori infection in Vietnam. Vietnamese J Gastroenterol 2012;7:1929-1940.

68. Malfertheiner P, Megraud F, O'Morain CA, et al. Management of 
Helicobacter pylori infection-the Maastricht V/Florence Consensus Report. Gut 2017;66:6-30.

69. Fallone CA, Chiba N, van Zanten SV, et al. The Toronto consensus for the treatment of Helicobacter pylori Infection in adults. Gastroenterology 2016;151:51-69.

70. Trung TT, Duc QT, Huong LK. The effectiveness of EAL and EBMT regimens as the second-line therapies in Helicobacter pylori eradication. Vietnamese J Gastroenterol 2008;3:730-735.

71. Vinh NT. Evaluation of the effectiveness of the second line therapies EAC and EBMT for Helicobacter pylori eradication. J Pract Med 2011;4:23-26.

72. Hue DN, Huy TV, Hai NT. Chronic Helicobacter pylori gastritis: the eradication efficacy of the Bismuth containing quadruple regimen (EMBT). Vietnamese J Gastroenterol 2016;9:2862-2871.

73. Di BQ, Thang HT. A study to assess efficacy of triple therapy with levofloxacin-based regime in eradication of Helicobacter pylori. J Med Pharm 2011;4:35-41.

74. Thang HT, Anh HT. Evaluating the efficacy of Rabeprazole-Levofloxacin-Tinidazole on chronic gastritis patients with positive Helicobacter pylori. Vietnamese J Gastroenterol 2001;9:2629-2636.

75. Hoan PQ. Study on prevalence and some biological characteristics of Helicobacter pylori in patients with duodenal ulcer before and after treatment [Ph.D. thesis]. Military Medical Academy: Hanoi, 2001. p. 32-58.

76. Vinh NT. Study on the therapeutic effects of three regimens: OAM, OAC, OMC in H. pylori-positive duodenal ulcer and the effect of drug resistance on these regimens [Ph.D. thesis]. Military Medical Academy: Hanoi, 2003. p. 25-67.

77. Nhan LDM, Mai VTC. Antibiotic resistance of Helicobacter pylori in patients with peptic ulcer disease. J Med Hochiminh City 2006;10:73-75.

78. Thinh NV, Hanh NH, Nguyet NT, et al. Antibiotic resistance of Helicobacter pylori in patients with duodenal ulcer in the first 6 months of 2009. J Pract Med 2009;660:14-18.

79. Nguyet NT, Hanh NH. Investigation of resistance to Helicobacter pylori isolates from patients with chronic gastritis, peptic ulcer and gastric cancer. J Pract Med 2010;712:20-22.

80. Toan ND, Thinh NV, Nguyet NT, et al. The situation of Helicobacter pylori resistance to antimicrobial susceptibility in patients with gastritis and duodenal ulcer. Vietnamese $\mathrm{J}$ Gastroenterol 2012;7:1783-1789.

81. Minh DC, Hoang BH. Evaluate antibiotic resistance of Helicobacter pylori cultured from gastro-duodenal ulcer patients failed with eradication. Vietnamese J Gastroenterol 2014;9:2358-2366.

82. Hue DN. Studies on the resistance of clarithromycin and levofloxacin of Helicobacter pylori by E test and the efficacy of EBMT in chronic gastritis [Ph.D. thesis]. Hue University of Medicine and Pharmacy: Hue, 2018. p. 26-47.

83. Megraud F, Coenen S, Versporten A, et al. Helicobacter pylori resistance to antibiotics in Europe and its relationship to antibiotic consumption. Gut 2013;62:34-42.

84. Kuo YT, Liou JM, El-Omar EM, et al. Primary antibiotic resis- tance in Helicobacter pylori in the Asia-Pacific region: a systematic review and meta-analysis. Lancet Gastroenterol Hepatol 2017;2:707-715.

85. Lee JW, Kim N, Kim JM, et al. Prevalence of primary and secondary antimicrobial resistance of Helicobacter pylori in Korea from 2003 through 2012. Helicobacter 2013;18:206-214.

86. O'connor A, Taneike I, Nami A, et al. Helicobacter pylori resistance to metronidazole and clarithromycin in Ireland. Eur J Gastroenterol Hepatol 2010;22:1123-1127.

87. De Francesco V, Giorgio F, Hassan C, et al. Worldwide H. pylori antibiotic resistance: a systematic review. J Gastrointestin Liver Dis 2010;19:409-414.

88. Ghotaslou R, Leylabadlo HE, Asl YM. Prevalence of antibiotic resistance in Helicobacter pylori: a recent literature review. World J Methodol 2015;5:164-174.

89. Karczewska E, Wojtas-Bonior I, Sito E, Zwolińska-Wcisło M, Budak A. Primary and secondary clarithromycin, metronidazole, amoxicillin and levofloxacin resistance to Helicobacter pylori in southern Poland. Pharmacol Rep 2011;63:799-807.

90. Chang WL, Sheu BS, Cheng HC, Yang YJ, Yang HB, Wu JJ. Resistance to metronidazole, clarithromycin and levofloxacin of Helicobacter pylori before and after clarithromycin-based therapy in Taiwan. J Gastroenterol Hepatol 2009;24:1230-1235.

91. Selgrad M, Tammer I, Langner C, et al. Different antibiotic susceptibility between antrum and corpus of the stomach, a possible reason for treatment failure of Helicobacter pylori infection. World J Gastroenterol 2014;20:16245-16251.

92. Cuadrado-Lavín A, Salcines-Caviedes JR, Carrascosa MF, et al. Levofloxacin versus clarithromycin in a 10 day triple therapy regimen for first-line Helicobacter pylori eradication: a single-blind randomized clinical trial. J Antimicrob Chemother 2012;67:22542259.

93. Hung IF, Chan P, Leung S, et al. Clarithromycin-amoxycillincontaining triple therapy: a valid empirical first-line treatment for Helicobacter pylori eradication in Hong Kong? Helicobacter 2009;14:505-511.

94. Molina-Infante J, Perez-Gallardo B, Fernandez-Bermejo M, et al. Clinical trial: clarithromycin vs. levofloxacin in first-line triple and sequential regimens for Helicobacter pylori eradication. Aliment Pharmacol Ther 2010;31:1077-1084.

95. Iacopini F, Crispino P, Paoluzi OA, et al. One-week once-daily triple therapy with esomeprazole, levofloxacin and azithromycin compared to a standard therapy for Helicobacter pylori eradication. Dig Liver Dis 2005;37:571-576.

96. Li Y, Huang X, Yao L, Shi R, Zhang G. Advantages of Moxifloxacin and Levofloxacin-based triple therapy for second-line treatments of persistent Helicobacter pylori infection: a meta analysis. Wien Klin Wochenschr 2010;122:413-422.

97. Nam PT, Huy TV, Hoa TT, et al. Antibiotic resistance of Helicobacter pylori with E-test in central region of Vietnam in two years 2012-2013. Vietnamese J Gastroenterol 2013;8:21222132. 
98. Toan ND, Thinh NV, Nguyet NT, et al. Helicobacter pylori gene mutation associated with primary resistance to clarithromycin in duodenal ulcer patients. Vietnamese J Gastroenterol 2013;8:19461951.

99. Trung NT, Toan ND, Long T, et al. Establishing a molecular biology procedure for detecting Helicobacter pylori. Vietnamese $\mathrm{J}$ Gastroenterol 2013;8:1990-1996.

100. Trung TT, Anh NT, Khiem TT. Primary study of clarithromycin and levofloxacin resistant mutation of $\mathrm{H}$. pylori by gene sequencing. Vietnamese J Gastroenterol 2014;9:2367-2375.

101. Dung HD, Binh TT, Tung NL, et al. Characterization of point mutations in 23s rRNA gene in Clarithromycin resistant Helicobacter pylori. Vietnamese J Gastroenterol 2014;9:2384-2389.

102. Doanh PN, Huy TV, Thi HTM. Clarithromycin resistance point mutation of H. pylori in Quang Ngai Province. Vietnamese J Gastroenterol 2014;9:2620-2628. 